\title{
The influence of relatedness and display effort on the mate choice of captive female American kestrels
}

\author{
JAMES R. DUNCAN \& DAVID M. BIRD \\ Macdonald Raptor Research Centre, Macdonald Campus of McGill University, 21, 111 Lakeshore \\ Road, Ste Anne de Bellevue, Quebec H9X 1CO. Canada
}

\begin{abstract}
Female American kestrels, Falco sparverius, were given the opportunity to choose between two males differing with respect to relatedness and nestling experience. Females did not discriminate against sibling males when choosing mates. Male display activity (number of nestbox inspections) was recorded and significantly more females chose the most active male. American kestrels suffer high yearly mortality, and the scarcity of suitable nesting cavities limits their breeding densities. Thus, there may be little selection pressure for incest avoidance by means of kin recognition. However, male display effort may play a role in the choice of mates.
\end{abstract}

The primary goal of mate choice studies has been to demonstrate that natural selection favours mechanisms enabling individuals to choose mates of the highest quality. Selection pressures have operated in a variety of ways on different species to produce a continuum of discriminatory abilities. These range from indiscriminate mass spawnings of certain fish (Bond 1979) to finely tuned choice mechanisms involving genotypes, such as kin recognition (Bateson 1983). Not surprisingly, investigators have revealed a variety of cues organisms use to choose mates. Grant \& Colgan (1983) reviewed factors influencing female choice, including resources provided (e.g. courtship feeding; Nisbet 1973) and defended (e.g. nest sites; Pleszczynska 1978; Garson 1980) by the male. These factors reflect aspects of male quality that directly affect female fitness.

In contrast, phenotypic markers of genetic quality may affect the fitness of a female's offspring (Howard 1978). Examples include body size (Hanson \& Smith 1967; McCauley \& Wade 1978) and relatedness (Bateson 1982). We investigated the influence of relatedness and male display effort on the mate choices of captive female American kestrels, Falco sparverius. Research was facilitated by the availability of a large pedigreed colony maintained at the Macdonald Raptor Research Centre of McGill University (Bird 1982). This species breeds readily in captivity and is sexually mature in its first spring.

Halliday (1983) defined mate choice as any pattern of behaviour, shown by members of one sex, that leads to their being more likely to mate with certain members of the opposite sex than with others'. Behaviour indicative of American kestrel pair-bond formation during the pre-nesting period has been well documented (Willoughby \& Cade 1964; Balgooyen 1976) and is readily exhibited in captivity (Willoughby \& Cade 1964; Olendorff 1968).

\section{METHODS}

A description of the annual maintenance and captive breeding procedures for the McGill kestrel colony is provided by Bird (1982). In the 1983 and 1984 breeding seasons, a total of 35 sexually mature females from 22 clutches was studied. Females $(N=31)$ from 18 clutches were reared with their siblings by their natural parents. Four females, from four clutches, were separated and reared individually by foster parents. In the fall the birds were overwintered in flight pens measuring $7.5 \times 6.5 \times 2.5 \mathrm{~m}$, each containing up to 30 individuals of the same sex. Birds were fed day-old cockerels supplemented every 2 days with dietary limestone or with SA-37 vitamin/mineral supplements (Roger-STB Division of BTI Products, Inc., Montreal, Quebec) every other day. All birds were exposed to a natural photoperiod.

From 25 April to 17 May 1983, and from 9 April to 2 May 1984, females were given the opportunity to choose between a male sibling and an unrelated male of the same age and breeding experience. Each female was tested once with each of her male 


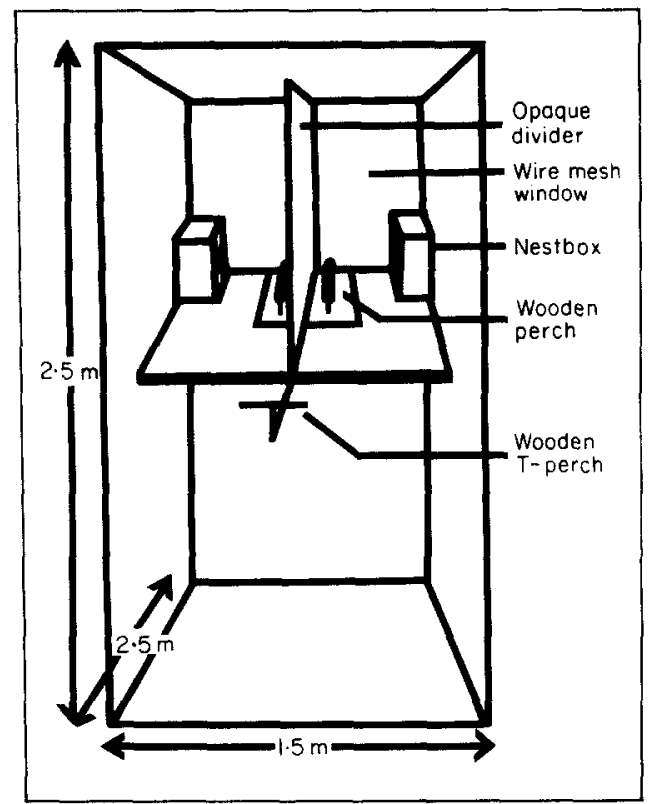

Figure. 1. Test pen used in mate choice experiments for captive American kestrels.

siblings, yielding a total of 50 tests. Unrelated males had a co-ancestry coefficient less than 0.02 with respect to the test female (Pirchner 1983).

\section{Apparatus}

Mate choices were determined in isolated test pens (Fig. 1) measuring $2.5 \times 1.5 \times 2.5 \mathrm{~m}$, each consisting of an opaque polyethylene divider resting on a masonite platform (Bird \& Goldblatt 1981). A wooden nestbox with shavings and a wooden perch to which a male was tethered in a modified falconer's fashion was located on each side of the divider. Males had access to their nestboxes, but were isolated visually from each other. A wooden T-perch was attached to the edge of the platform. The perch extended far enough to give the free-flying female a view of both tethered males simultaneously. The birds were observed through one-way mirrors $(30 \times 5 \mathrm{~cm})$ located in the door of each pen.

\section{Test Schedule}

Over a test period lasting 8 days, males were tethered in place on day 1 and were allowed to acclimate for 2 days. Observations began at least $1 \mathrm{~h}$ after the introduction of test females on the morning of day 3. Each pen was observed for three 20-min intervals per day: morning, noon and afternoon, for 5 days. The sequence in which the pens were observed was random. The male's position within each pen was switched half-way through the observation period to ensure that a female was not choosing a side as opposed to a male. Each day, birds were fed day-old cockerels ad libitum before the morning observation interval. After testing, the birds were returned either to the flight pens and maintained unisexually, or relocated for the next test period. None of the birds used more than once was tested twice in the same pen.

\section{Choice Criteria}

The four criteria described below vary in their relative strength as indicators of American kestrel pair-bond formation during the pre-nesting period (Willoughby \& Cade 1964; Balgooyen 1976). The values of all criteria were compared before and after the males' positions were switched to score the test females as having chosen a mate, chosen a side, or having made no choice.

(1) Location of the female. American kestrels are quite sociable in the pre-nesting period, often perching in contact with each other. This criterion was summarized as a percentage of the total observed time spent by a female with either one of the males or in a neutral area. She was considered to be interested in a male when she remained within his reach for at least $1 \mathrm{~min}$.

(2) Nestbox inspections. The direction of attention and activity toward the nest site is important in establishing an attachment of the mates to a mutually acceptable nest and in stimulating the birds sexually (Willoughby \& Cade 1964). The female inspected a nestbox when she entered it or perched at its entrance with her head and shoulders inside. The frequency of this behaviour was recorded.

(3) Copulations. Female American kestrels solicit copulations with potential mates early in the pre-nesting period by leaning forward with the tail held at $45^{\circ}$ to the substrate (Willoughby \& Cade 1964). The mounting of the female by a male. together with subsequent copulatory movements, was recorded as a copulation. Unsuccessful attempts by the males to mount unsoliciting females were not recorded.

(4) Food-transfers. Courtship feeding functions 
to maintain previously established pair-bonds in most monogamous species (Nisbet 1973). A successful food-transfer was recorded if a female accepted food from a displaying male (Willoughby \& Cade 1964).

These behaviours, indicative of pair-bond formation, have been well documented (Willoughby \& Cade 1964; Balgooyen 1976) and are readily exhibited in captivity (Willoughby \& Cade 1964; Olendorff 1968). However, sometimes females are promiscuous early in the breeding season (Willoughby \& Cade 1964). We observed females inspecting the nestbox of both males in 37 of 50 tests and copulating with both males in 17 of 50 tests. In only one test out of 50 was a female observed to perform a food-transfer with each of the choice males. Food-transfers were therefore considered the most consistent indicator of a strong pair bond, as mentioned by Willoughby \& Cade (1964). A female was considered to have chosen a male if she received food-transfers from him. Food-transfers were observed in only 24 of the 50 tests, therefore, in the absence of this criterion a female's choice was the male with which she copulated more frequently. She was recorded as having made no choice if no copulations or food-transfers were observed. The frequency of nestbox inspections and the location of the female were used when necessary to resolve small frequency differences or inconsistencies in the copulation and food-transfer criteria. All four criteria were used to ensure that females were not choosing sides as opposed to males. If a female interacted more frequently with a different male after the sides were switched, she was recorded as having chosen a side. Tests in which a female made no choice $(N=9)$ or chose a side rather than a particular male $(N=8)$ were not included in the analysis.

\section{Male Display Effort}

Wild American kestrel males display to distant females using a combination of vocalizations, aerial manoeuvres and nest-cavity inspections (Willoughby \& Cade 1964; Balgooyen 1976). Males were prevented from making aerial displays in these experiments, but vocalizations and nestbox inspections were common. While vocalizations were difficult to credit to specific males, the frequency with which each male inspected his nestbox, while in view of the female, provided an estimate of his display effort. A male inspected his nestbox
Table I. Frequency (mean $\pm \mathrm{SD}$ ) of female American kestrel interactions for 50 sibling versus non-sibling mate choice tests

\begin{tabular}{lcccc}
\hline & \multicolumn{4}{c}{ Mate choice criteria } \\
Test male & $\begin{array}{c}\text { Location } \\
\text { of female }\end{array}$ & $\begin{array}{c}\text { Nestbox } \\
\text { inspections }\end{array}$ & $\begin{array}{c}\text { Copula- } \\
\text { tions }\end{array}$ & $\begin{array}{c}\text { Food } \\
\text { transfers }\end{array}$ \\
\hline Sibling & $44.2 \pm 34.7$ & $4.0 \pm 5 \cdot 2$ & $3.4 \pm 4 \cdot 6$ & $0.2 \pm 0.5$ \\
Non-sibling & $54.6 \pm 39.7$ & $4.9 \pm 4.3$ & $3.7 \pm 4 \cdot 3$ & $0.4 \pm 0.9$ \\
\hline
\end{tabular}

when he entered it or perched at its entrance with his head and shoulders inside.

The number of nestbox inspections by males that were immediately followed by at least one interaction with the female was recorded. An 'interaction' refers to one of the mate choice criteria previously described.

To determine whether early nestling experience or male display effort influenced the proportion of females that chose siblings, the Fisher exact probability test (Daniel 1978) was used. The two-tailed normal approximation to the binomial (Ostle \& Mensing 1975) was used to resolve whether females chose either non-siblings or more active males significantly more often than if they had done so at random. This same test was used to determine if there was a significant difference in the total number of nestbox inspections performed by the test female's male siblings and the non-related males. The level of significance was 0.05 for all the above tests.

\section{RESULTS}

The data yielded consistent results when statistically analysed separately for each year and therefore data were pooled. Mean values of female interactions with siblings versus non-siblings were not significantly different $(Z<1.96)$ for each of the mate choice criteria (Table I). In 50 tests, 33 females chose a male, nine made no choice, and eight chose a side.

There was no significant difference $(P=0 \cdot 558$; Fisher exact probability test) in the proportion of females that chose brothers (13) for those birds reared together with their siblings (11) and those raised apart (2). Females did not choose unrelated males significantly more often $(20)$ than if they had done so at random $(P=0 \cdot 222$; two-tailed normal approximation to the binomial). 
Eleven females were tested twice, once with each of two male siblings. The results of the second tests were not significantly different $(P=0.9$, binomial) from the expected if the second test was considered independent of the first. When the first choices of the females tested were analysed separately our results did not change. For example, considering those females that chose males (25), the proportion choosing siblings (11) was not significantly different from that of those choosing non-related males $(P=0.395$, binomial).

In the sibling versus stranger tests there were 628 nestbox inspections by males. There was no significant difference $(P=0 \cdot 13$; two-tailed normal approximation to the binomial) between the total number of nestbox inspections by the test female's male siblings (295) and the total number by nonrelated males (333). Of all the nestbox displays done by males, $35 \%$ resulted in at least one interaction (see mate choice criteria, Methods) with the female. Nestbox inspection values for individual males ranged from 0 to 20 with a mean of $6 \cdot 29 \pm 4.94$ (SD).

There were 31 relatedness tests in which a female made a choice and the number of nestbox inspections by the two males differed. Significantly more females (23) chose the more active male $(P=0.007$; two-tailed normal approximation to the binomial). In the 14 tests where the difference in the number of nestbox inspections between pairs of males was five or greater, the female always chose the more active male. The number of females that chose siblings (12) which were either the more (nine) or less (three) active of the two males offered was not significantly different from that of those who chose non-related males which were either more (14) or less (five) active $(P=0.638$. Fisher's exact probability test $)$.

\section{DISCUSSION}

\section{Relatedness}

The optimal outbreeding hypothesis, as elaborated by Bateson (1983), predicts that individuals may avoid choosing siblings as mates due to the genetic costs. Inbreeding costs are also known as inbreeding depression or a decrease in the mean level of characters related to fitness, such as reduced fertility or hatchability (Falconer 1982). Recent studies have shown that some avian (Koenig \& Pitelka 1979; Bateson 1982) and mammalian
(Dewsbury 1982; Hoogland 1982; Duncan et al. 1984; Gavish et al. 1984) species demonstrate behavioural discrimination against siblings when choosing mates. This ability requires the organism to assess the degree of relatedness of its potential suitors. Mechanisms of kin recognition, as reviewed by Blaustein (1983) and Holmes \& Sherman (1983), may be based on the familiarity of conspecifics (Bateson 1983; Gavish et al. 1984), or on a genetic component (Hepper 1983), such as phenotypic matching or recognition alleles. Female American kestrels apparently lack such a mechanism or at least did not employ it to avoid incestuous sibling mate choices. There was little difference between the total display effort of the test female's male siblings and that of non-related males. Relatedness did not affect the choice of more- or less-active males. Hence, variety in male display behaviour apparently did not reduce the occurrence of inbreeding.

Holmes \& Sherman (1983) believed that mechanisms of kin recognition are selected under rare conditions. They stated that 'Dispersal and mortality are the crucial demographic parameters, because kin selection will have acted only on those categories of relatives that have consistently coexisted in proximity to one another across evolutionary time, so that social interactions have regularly occurred between them.'

Henny (1972) estimated that American kestrels suffer high mortality, both as adults $(47 \%)$ and as juveniles $(69 \%)$. While they appear to be philopatric (Bowman et al. 1987) a scarcity of suitable nest cavities limits their breeding densities (Hamerstrom et al. 1973). Thus, American kestrels probably have experienced little, if any, selection pressure to develop a mechanism of kin recognition to avoid incest. That early nestling experience had no effect on subsequent mate choice is therefore not surprising. Of 271 wild American kestrels banded over 4 years at Ste Anne de Bellevue, Quebec, only one juvenile female returned to its natal area and bred with its father (Bowman et al. 1987).

Although the frequency of incest may be reduced somewhat by differential dispersal of young organisms, incest avoidance is not necessarily the driving force. According to Moore \& Ali (1984) and Liberg \& von Schantz (1985), incest avoidance via sexual dispersal patterns are epiphenomenal consequences of intrasexual competition and territory choice. Cases have been reported in which young peregrine. $F$. peregrinus, and prairie falcons. 
$F$. mexicanus, were driven away from their natal cliffs the following spring by their parents (Newton 1979).

Newton \& Marquiss (1982), in a study on the fidelity to breeding area and to mate in sparrowhawks, Accipiter nisus, found that yearlings moved more frequently and farther than older birds. Additionally, males exhibited greater residency than females. The movement patterns of this nonmigratory raptor species are not necessarily due to fidelity to the mate or nest site, but are expressed in response to food resources and territory quality (Newton \& Marquiss 1982). This supports Liberg \& von Schantz's (1985) prediction for male-biased philopatry in monogamous birds. As information on the paternity of the sparrowhawks was not available, possible incestuous pairings could not be detected.

\section{Male Display Effort}

The mate choice criteria previously described are well-established indicators of American kestrel pair-bond formation. Given the importance of the nest cavity to the successful reproduction of this species, nestbox inspections are essential displays if a male is to obtain a mate. Of all the nestbox inspections by males, $35 \%$ were followed immediately by at least one interaction with the female, and significantly more females chose the more active male. The frequency of nestbox inspections by males probably reflects a more general courtship activity level and accounts for a female's preference for the male that appears to have a greater interest in her. Males showed variable display values, indicating that male choice may have had some influence on the test female's preference. The level of activity may indicate the male's potential reproductive effort. Grant \& Colgan (1983) found that female Johnny darters, Etheostoma nigrum, preferred males that moved farther out from their nests to respond to intruders. Female European wrens, Troglodytes troglodytes, preferred males exhibiting the highest pre-fertilization reproductive effort, as reflected by the number of complete but vacant nests on a male's territory (Garson 1980). Since these males had higher reproductive success in both these examples, choosy females increased their own fitness. The intensity of display by male American kestrels may also be indirect evidence of genetic quality (Burley \& Moran 1979).

\section{Parental Investment and Mate Choice}

The results of this study agree with Grant \& Colgan's (1983) statement that the 'genetic quality of the male may be less important in influencing mate choice than factors which directly affect the survival of the females' offspring'. These factors are aspects of male quality directly affecting the fitness of the female. These factors are important to the reproductive success of female American kestrels, which depends on the presence of a suitable nesting cavity and on the male's ability to provide food during most of the breeding season (Bent 1938; Willoughby \& Cade 1964). Parental investment by male raptors is high before, during, and after fertilization (Newton 1979). Males may vary considerably in their ability to provide and defend resources due to factors such as age or experience. Thus, the benefits to a discriminating female would be large under these circumstances. In general, as male parental investment increases, both the benefits and costs to choosy females increase.

Natural history, local conditions (e.g. island versus mainland populations) and male parental investment influence the relative costs and benefits to choosy females. Given the scarcity of suitable nesting cavities (Hamerstrom et al. 1973), perhaps the search costs for alternative male American kestrels outweigh the benefits (Bengtsson 1978). In this case, selection would not favour choosy females. The paucity of suitable nesting cavities and high mortality probably reduce inbreeding costs enough that behavioural incest-avoidance mechanisms have not been selected. Of the various mate choice strategies described by Wittenberger (1983), wild female kestrels most probably employ a threshold-criterion-based tactic: females choose only males able to provide sufficient resources for successful reproduction.

\section{ACKNOWLEDGMENTS}

We would like to thank the many graduate students, summer interns and employees of the Macdonald Raptor Research Centre for their technical assistance. We wish to express our gratitude to $\mathrm{J}$. Cypher and to Drs J. R. Bider, G. J. Doucet, P. Laguë and R. D. Titman for their meticulous scrutiny of various drafts of the manuscript. This research was supported by the Natural Sciences and Engineering Research Council of Canada and La Ministère du Loisir, de la Chasse, et de la Pêche 
du Québec with grants to Dr Bird. This is the Macdonald Raptor Research Centre Scientific Publication No. 42.

\section{REFERENCES}

Balgooyen, T. G. 1976. Behaviour and ecology of the American kestrel (Falco sparverius L.) in the Sierra Nevada of California. Univ. Calif. Publs Zool., 103, 185.

Bateson, P. 1982. Preferences for cousins in Japanese quail. Nature, Lond., 295, 236-237.

Bateson, P. 1983. Optimal outbreeding. In: Mate Choice (Ed. by P. Bateson), pp. 257-278. Cambridge: Cambridge University Press.

Bengtsson, B. O. 1978. Avoiding inbreeding: at what cost? J. theor. Biol., 73, 439-444.

Bent, A. C. 1938. Life histories of North American birds of prey, part 2. U.S. natn Mus. Bull, 170, 1-482.

Bird, D. M. 1982. The American kestrel as a laboratory research animal. Nature, Lond., 299, 300-301.

Bird, D. M. \& Goldblatt, C. J. 1981. Influence of crossfostering on mate selection in captive kestrels. In: Recent Advances in the Study of Raptor Diseases (Ed. by J. E. Cooper \& A. G. Greenwood), pp. 41-44. London: Chiron.

Blaustein, A. R. 1983. Kin recognition mechanisms: phenotypic matching or recognition alleles? Am. Nat., 121, 749-754.

Bond, C. E. 1979. Biology of Fishes. London: W. B. Saunders.

Bowman, R., Duncan, J. R. \& Bird, D. M. 1987. Dispersal and inbreeding avoidance: are they related? In: The Ancestral Kestrel (Ed. by D. M. Bird \& R. Bowman), pp. 145-150. Ste-Anne-de-Bellevue, Quebec: Raptor Research Foundation.

Burley, N. \& Moran, N. 1979. The significance of age and reproductive experience in the mate preferences of feral pigeons, Columba livia. Anim. Behav., 27, 686-698.

Daniel, W. W. 1978. Applied Nonparametric Statistics. Boston: Houghton Mifflin.

Dewsbury, D. A. 1982. Avoidance of incestuous breeding between siblings in two species of Peromyscus mice. Biol. Behav., 7, 157-169.

Duncan, P., Feh, C., Gleize, J. C., Malkas, P. \& Scott, A. M. 1984. Reduction of inbreeding in a natural herd of horses. Anim. Behav., 32, 520-527.

Falconer, D. S. 1982. Introduction to Quantitative Genetics. 2nd. edn. London: Longman.

(jarson, P. J. 1980. Male behaviour and female choice: mate selection in the wren? Anim. Behav., 28, 491-502.

Gavish, L., Hofmann, J.E. \& Lowell, L.G. 1984. Sibling recognition in the prairie vole, Microtus ochrogaster. Anim. Behav., 32, 362-366.

Grant, J. W. A. \& Colgan, P. W. 1983. Reproductive success and mate choice in the Johnny darter, Etheostoma nigrum (Pisces: Percidae). Can. J. Zool., 61, 437. 446.

Halliday, T. R. 1983. The study of mate choice. In: Mate
Choice (Ed. by P. Bateson), pp. 3-32. Cambridge Cambridge University Press.

Hamerstrom, F., Hamerstrom, F. N. \& Hart, J. 1973. Nest boxes: an effective management tool for kestrels. J. Wildl. Mgmt, 37, 400-403.

Hanson, A. J. \& Smith, H. D. 1967. Mate selection in a population of sockeye salmon (Oncorhynchus nerka) of mixed age groups. J. Fish. Res. Bd Can., 24, 1955 1977.

Henny, C. J. 1972. An analysis of the population dynamics of selected avian species. U.S. Fish Wild. Serv. Res. Rep., 1, 23-28.

Hepper, P. G. 1983. Sibling recognition in the rat. Anim Behav., 31, 1177-1191.

Holmes, W. G. \& Sherman, P. W. 1983. Kin recognition in animals. Am. Scient., 71, 46-55.

Hoogland, J. L. 1982. Prairie dogs avoid extreme inbreed. ing. Science, N.Y., 215, 1639-1641.

Howard, R. D. 1978. The evolution of mating strategies in bullfrogs, Rana catesbeiana. Evolution, 32, 850-871.

Koenig, W. D. \& Pitelka, F. A. 1979. Relatedness and inbreeding avoidance: counterploys in the communally nesting acorn woodpecker. Science, N.Y., 215, 1103 1105.

Liberg, O. \& von Schantz, T. 1985. Sex-biased philopatry and dispersal in birds and mammals: the Oedipus hypothesis. Am. Nat., 126, 129-135.

McCauley, D. E. \& Wade, M. J. 1978. Female choice and the mating structure of a natural population of the soldier beetle Chauliognathus pennsylvanicus. Evoluion, 32, $771-775$.

Moore, J. \& Ali, R. 1984. Are dispersal and inbreeding avoidance related? Anim. Behav., 32, 113-119.

Newton, I. 1979. Population Ecology of Raptors. Vermil lion: Buteo Books.

Newton, I. \& Marquiss, M. 1982. Fidelity to breeding area and mate in sparrowhawks, Accipiter nisus. $f$. Anim. Ecol., 51, 327-341.

Nisbet, I. C. T. 1973. Courtship-feeding, egg-size and breeding success in common terns. Nature, Lond., 241, $141-142$.

Olendorff, R. R. 1968. A contribution to the breeding behaviour of the American kestrel in captivity. Raptor Res. News, 2, 77-92.

Ostle, B. \& Mensing, R. W. 1975. Statistics in Research. Ames: Iowa State University Press.

Pirchner, F. 1983. Population Genetics in Animal Breeding. 2nd edn. San Francisco: W. H. Freeman.

Pleszczynska, W. K. 1978. Microgeographic prediction of polygyny in the lark bunting. Science. N.Y. 201, 935937.

Willoughby, E. J. \& Cade, T. J. 1964. Breeding behavior of the American kestrel (sparrow hawk). Living Bird, 3 , 75-96.

Wittenberger, J. F. 1983. Tactics of mate choice. In: Mate Choice (Ed. by P. Bateson), pp. 435-447. Cambridge: Cambridge University Press.

\author{
(Received 14 October 1986; revised 5 March 1988: \\ MS. number: 44728)
}

